\title{
The Evolution of Microstructure for Ductile Iron Treated under Different Thermal Cycles Using Electrolytic Plasma Treatment
}

\author{
A. AYdaY* And M. DuRman \\ Sakarya University, Faculty of Engineering, Department of Metallurgical and Materials Engineering \\ Sakarya, 54187, Turkey
}

\begin{abstract}
The effects of the thermal cycles on the microstructures and properties of ductile iron modified by electrolytic plasma treatment were investigated. Microstructure changes occurring in the modified surface were characterized with scanning electron microscopy, X-ray diffractometry techniques. Martensitic structure evolved in the heat affected zone and ledeburite structure was produced in the molten zone of the ductile iron. Microhardness of the treated specimens improved considerably as compared to the original sample. X-ray diffraction clearly revealed the formation of a martensite phases in the modified zone.
\end{abstract}

DOI: 10.12693 /APhysPolA.125.577

PACS: 68.35.bd, 52.50.-b, 81.40.Cd, 81.40.Ef, 81.30.Kf

\section{Introduction}

In many engineering applications, surface coatings and other methods of surface treatment are used to increase the life of components exposed to abrasion or erosion. Coatings and surface treatments, which affect material properties, vary greatly in depth. Surface engineering is an economic method for the production of materials, tools, and machine parts with the required surface properties, such as wear and corrosion resistance [1-3].

Among other technologies for surface engineering, the process of plasma surface hardening is gaining an increasingly wide acceptance. Electrolytic plasma treatment (EPT) is a special heat treatment process employing electrolysis in an aqueous solution under particular conditions, for instance voltage, current, electrolyte, duration, and heating-quenching rate. During the process, acting as a high voltage (impulse), to heat the surface of the material to the austenitization temperature, in the meantime the bulk material acts as a low voltage (pause) to cool down the surface rapidly, a layer of hardened martensite is formed on the surface. Heating the surface and then cooling the surface in the process called one thermal cycle [4-6]. In this research, thermal cycles affect was investigated. The aim of the present work was to investigate the effect of modification thickness on microstructure, hardness of ductile iron.

\section{Experimental procedure}

Specimens of the ductile iron were produced in a commercial foundry. The chemical composition of the

\footnotetext{
*corresponding author; e-mail: aayday@sakarya.edu.tr
}

iron was $3.22 \% \mathrm{C}, 2.51 \% \mathrm{Si}, 0.104 \% \mathrm{Mn}, 0.768 \% \mathrm{Cu}$, $0.0444 \%$ Cr, $0.060 \%$ P, $0.011 \%$ S, $0.0411 \%$ Mg. Hardness of the ductile iron as-cast microstructure was $270 \mathrm{HV}_{0.2}$.

Electrolytic plasma treatment parameters.

TABLE I

\begin{tabular}{c|c|c|c|c|c}
\hline $\begin{array}{c}\text { Parameter } \\
\text { code }\end{array}$ & $\begin{array}{c}\text { Electrolytic } \\
\text { solution }\end{array}$ & $\begin{array}{c}\text { Impulse } \\
\text { [V] }\end{array}$ & $\begin{array}{c}\text { Pause } \\
{[\mathrm{V}]}\end{array}$ & $\begin{array}{c}\text { Total time } \\
{[\mathrm{s}]}\end{array}$ & $\begin{array}{c}\text { Thermal } \\
\text { cycle }\end{array}$ \\
\hline $\mathrm{A}$ & $\mathrm{Na}_{2} \mathrm{CO}_{3} ; 12 \%$ & 310 & 250 & $(3-3) \times 4-24 \mathrm{~s}$ & 4 \\
$\mathrm{~B}$ & $\mathrm{Na}_{2} \mathrm{CO}_{3} ; 12 \%$ & 310 & 250 & $(3-3) \times 5-30 \mathrm{~s}$ & 5 \\
$\mathrm{C}$ & $\mathrm{Na}_{2} \mathrm{CO}_{3} ; 12 \%$ & 310 & 250 & $(3-3) \times 6-36 \mathrm{~s}$ & 6
\end{tabular}

Specimens of as-cast ductile iron were EPT modified in accordance with the recommended experiment plan shown in Table I. For microstructural investigations, the samples were cross-sectioned and, after standard metallographic treatments, polished using $0.1 \mathrm{~mm}$ alumina polishing powder suspended in distilled water.

Etching was performed using a $2 \%$ nital solution and the microstructure was investigated by an optical microscope (OM NIKON ECLIPSE L150). Different initial microstructures before EPT were achieved by different pretreatments. The microhardness of cross-sectioned welded layers was measured using a Vickers microhardness tester under an applied load of $200 \mathrm{~g}$.

\section{Results and discussion}

The microstructure in the modified area is dependent on the heating and cooling cycles that take place during the process. After the process, three or four different zones within the surface area occur, at the top a completely martensitic structure develops, which is referred to as the hardened zone (HZ), the heat affected zone (TZ) consists of partly austenized and eventually hardened microstructure, and the rest is base material (BM) which did not transform during the EPT. In the fourth layer on the surface the melted zone (MZ) consists of a maximum thermal cycling. 
The surface temperature, modified depth and the modified structure (melted or hardened) on the cross-sectional plane perpendicular to modified surface as a function of EPT thermal cycles, heating and cooling time.

The main constituents obtained in the hardened layer of $A$ and $B$ code samples were coarse martensite together with small quantities of retained austenite, maintaining the graphite nodules unaltered. The microstructure in the remelted surface layer ( $C$ code) is fine grained and consists of austenite dendrites with very fine dispersed cementite, together with a small proportion of martensite (Fig. 1).

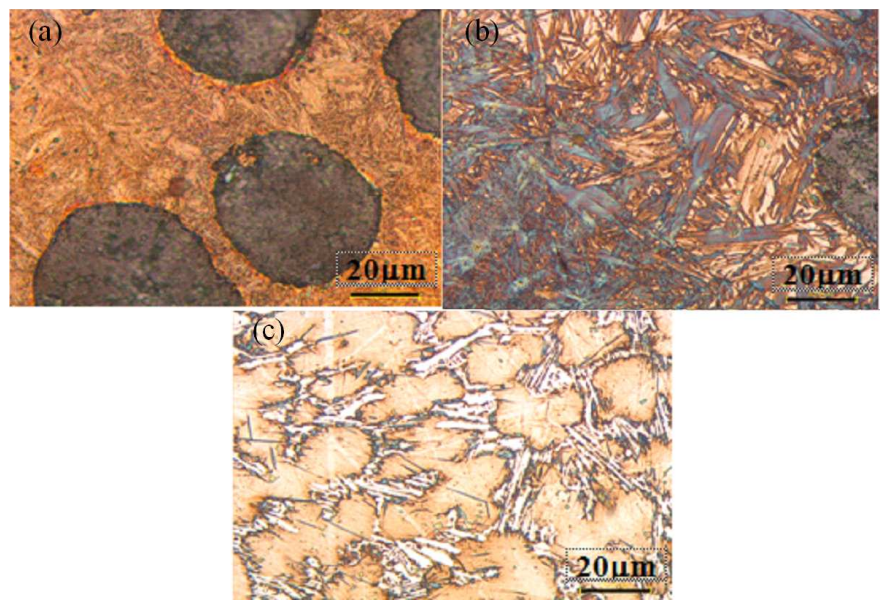

Fig. 1. Surface microstructure of EPT modified ductile iron. (a) $A$ code, (b) $B$ code, (c) $C$ code samples.

EPT modified specimens properties.

TABLE II

\begin{tabular}{c|c|c|c|c|c}
\hline \hline $\begin{array}{c}\text { Parameter } \\
\text { code }\end{array}$ & $\begin{array}{c}\text { Thermal } \\
\text { cycle }\end{array}$ & $\begin{array}{c}\text { MVF } \\
{[\%]}\end{array}$ & $\begin{array}{c}\text { Max. surface } \\
\text { temperature } \\
{\left[{ }^{\circ} \mathrm{C}\right]}\end{array}$ & $\begin{array}{c}\text { Modified } \\
\text { layer depth } \\
{[\mu \mathrm{m}]}\end{array}$ & $\begin{array}{c}\text { Melted } \\
\text { layer depth } \\
{[\mu \mathrm{m}]}\end{array}$ \\
\hline $\mathrm{A}$ & 4 & 30.53 & 510 & 2280 & - \\
$\mathrm{B}$ & 5 & 47.4 & 800 & 3188 & - \\
$\mathrm{C}$ & 6 & 15.85 & 1100 & 5200 & 1000
\end{tabular}

Three different thermal cycles were used: 4,5 and 6 with the resulting martensitic volume fraction (MVF), temperature and modified depth are listed in Table II. Comparing data in Tables I and II it is clear that the thickness of the remelted layer depends on the thermal cycle during EPT and the minimum MVF consisted of remelted sample ( $C$ code).

Microhardness profiles measured in the cross-sectional plane of the EPT modified ductile iron are shown in Fig. 2. The result in Fig. 2 shows that the hardness of the modified samples increases with increase of the thermal cycle. As can be seen, the EPT modification raised the hardness at the specimen surfaces to $879-1046 \mathrm{HV}_{0.2}$. The hardness of the untreated specimens was assumed to be uniform, at $270 \mathrm{HV}_{0.2}$, throughout. The specimens $C$ code $15.85 \%$ MVF exhibited the best hardness. The reason for the high hardness in case of EPT melted sam-

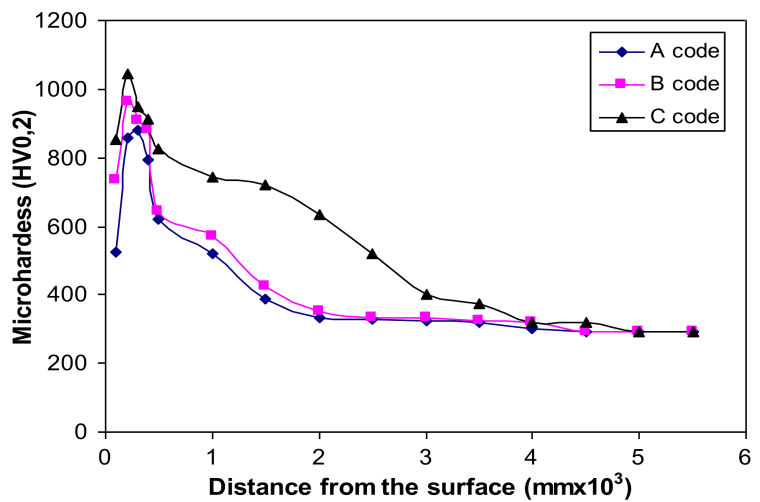

Fig. 2. Microhardness profile of EPT modified samples.

ples is the formation of fine dendrites and the ledeburite structure.

\section{Conclusion}

The main conclusions derived from the experimental results are the following.

The microstructure of the surface after EPT was finer and more homogeneous in comparison with the untreated material. The $\mathrm{HZ}$ consisted of martensite and some retained austenite areas with the graphite nodules, the HAZ mixed microstructure, consisted of martensite and pearlite. The MZ which is composed of ledeburite (martensite + cementite), also contained a small amount of residual austenite and a transition zone. The microstructure of the untreated material consists pearlite and graphite.

The microhardness of the ductile iron specimens increases considerably after EPT. The average microhardness of $C$ code sample is much higher than of $A$ and $B$ code samples. The results show that the thermal cycle increases microhardness of ductile iron markedly. EPT-treated ductile iron had about four times higher hardness than the untreated ductile iron.

\section{References}

[1] Q. Guo, H. Zhou, C. Wang, W. Zhang, P. Lin, N. Sun, L. Ren, Appl. Surf. Sci. 255, 6266 (2009).

[2] D. Suh, S. Lee, S. Kwon, Y. Koo, Metall. Mater. Trans. A 28, 1499 (1997).

[3] T. Slatter, H. Taylor, R. Lewis, P. King, Wear 267, 797 (2009).

[4] Y.N. Tyurin, A.D. Pogrebnjak, Surf. Coat. Technol. 142-144, 293 (2001).

[5] A.D. Pogrebnyak, O.P. Kul'ment'eva, A.P. Kobzev, Yu.N. Tyurin, S.I. Golovenko, A.G. Boiko, Tech Phys. Lett. 29, 312 (2003).

[6] S.F. Luk, T.P. Leung, W.S. Miu, I. Pashby, J. Mater Proc. Technol. 84, 189 (1998). 